\title{
Thick Film Laser Sintering: An Evidence for Two-step Process
}

\author{
Eduardo Antonelli ${ }^{1, *}$, Marcello Rubens Barsi Andreeta ${ }^{2}$, Eriton Rodrigo Botero ${ }^{3}$ and Antonio Carlos \\ Hernandes ${ }^{4}$
}

${ }^{1}$ Instituto de Ciência e Tecnologia, Universidade Federal de São Paulo, 12231-280, São Jose dos Campos, SP, Brazil

${ }^{2}$ Departamento de Engenharia de Materiais, Universidade Federal de São Carlos, CEP: 13565-905, São Carlos, SP, Brazil

${ }^{3}$ Faculdade de Ciências Exatas e Tecnologias, Universidade Federal da Grande Dourados, C.P. 364, 79804-970, Dourados, MS, Brazil

${ }^{4}$ Grupo Crescimento de Cristais e Materiais Cerâmicos, Instituto de Física de São Carlos, Universidade de São Paulo, C. P. 369, 13560-970, São Carlos, SP, Brazil

\begin{abstract}
The results for the sintering of $\mathrm{Bi}_{4} \mathrm{Ti}_{3} \mathrm{O}_{12}$ (BIT)-doped $\mathrm{BaTi}_{0.85} \mathrm{Zr}_{0.15} \mathrm{O}_{3}$ (BTZ) thick films, deposited by electrophoresis, using as heating source a $\mathrm{CO}_{2}$ laser are presented. The thermal process associated to the laser scanning sintering (LSS) acted in a similar way as a two-step-sintering process. This characteristic together with the high heating rate allowed us to obtain thick films with an average grain size of $200 \mathrm{~nm}$, high relative density $(\sim 96 \%)$ and with a homogeneous microstructure. The $\mathrm{X}$ ray diffraction profile analysis show evidences for $\mathrm{Bi}^{3+}$ replacing $\mathrm{Ba}^{2+}$ at the $\mathrm{A}$ sites.
\end{abstract}

Keywords: Ceramic material; sintering; thick films; laser-heated; nanomaterials; dielectrics.

\section{INTRODUCTION}

Research on ferroelectric and piezoelectric thick films (thickness above $20 \mu \mathrm{m}$ ) is of fundamental importance for the development of microelectromechanical systems (MEMS) due to its higher sensitivity, larger mechanical force and broader working frequency range when compared to thin films [1-3]. One of the most versatile techniques for thick films production is the electrophoretic deposition (EPD). Two features of this technique are the shaping of free standing objects and the possibility to deposit thick films on planar substrates. The process starts from liquid suspensions of nanometer size powders that are deposited through the application of direct current (DC) potentials. This method employs the phenomenon of the movement of colloidal particles suspended in a medium when subjected to an electric field $[2,3]$.

The quality of the thick films devices is directly dependent on the sinterization process after the deposition. Sintering is an important step in ceramic processing and it is a determinant factor for the microstructure and properties of the produced material. So far, the study of new techniques for sintering has been of great interest as it offers the possibility to optimize the density, grain sizes and other important ceramic characteristics $[4,5]$. As an example, we can mention the microwave sintering [6], spark-plasma sintering [7, 8],

*Address correspondence to this author at the Instituto de Ciência e Tecnologia, Universidade Federal de São Paulo, 12231-280, São Jose dos Campos, SP, Brazil; Tel: 55-21 33099591; Fax: 55-21 39218857;

E-mail: antonelli@unifesp.br two-step-sintering $[5,9]$ and the laser sintering $[10,11]$.The two-step-sintering has been particularly proposed as a simple and less expensive process where the grain growth in the final stage of the densification is suppressed thus allowing producing dense materials with nanometer-scale structure [5, 9]. In this technique, a first stage at high temperatures is used to obtain a critical density, and after this, a second stage at lower temperature is used to obtain high densities without grain growth. The suppression of the final-stage grains growth is achieved by exploiting the difference in kinetics between grain-boundary diffusion and grain-boundary migration [9]. The laser sintering has been proposed as a new process where the conventional heat source is replaced by a laser beam. The process involves less expensive cost and made it possible to obtain ceramics with small grains growth and optimal characteristics [11-13].

One of the most interesting materials studied for the production of ferroelectric thick films is the $\mathrm{BaTi}_{1-x} \mathrm{Zr}_{x} \mathrm{O}_{3}$ compound. Studies have shown that in appropriate amounts, $\mathrm{Zr}^{4+}$ induces an increase of the dielectric constant, tunability under biasing electric field and a reduction of the lowfrequency dielectric losses [14]. In this work, we present the production and laser sinterization results for pure and $\mathrm{Bi}_{4} \mathrm{Ti}_{3} \mathrm{O}_{12}$ (BIT) doped $\mathrm{BaTi}_{0.85} \mathrm{Zr}_{0.15} \mathrm{O}_{3}$ thick films. The films were deposited by electrophoresis and sinterized with a $\mathrm{CW}$ $\mathrm{CO}_{2}$ laser in scanning mode. Based on our results, we also present evidences that a two-step sintering process may take place in thick films laser sintering technique. 


\section{EXPERIMENTAL PROCEDURE}

$\mathrm{BaTi}_{1-\mathrm{x}} \mathrm{Zr}_{\mathrm{x}} \mathrm{O}_{3}(\mathrm{x}=0.15)(\mathrm{BTZ15})$ powders were prepared through a modified polymeric precursor (Pechini) method, starting from zirconium, titanium citrate and barium acetate solutions. The material was heat treated at $600{ }^{\circ} \mathrm{C}$ for an annealing time of $2 \mathrm{~h}$. The powder showed primary particles of $\sim 20 \mathrm{~nm}$ and agglomerates of $\sim 100 \mathrm{~nm}$, according to scanning electron microscopy (FEG-SEM) observations. Details of the powder preparation and structural characterization may be found in Ref. [15].

The suspensions with $2 \mathrm{~g} / 100 \mathrm{ml}$ concentration were prepared with BTZ15 powder in a mixture of acetylacetone (Acac) and ethanol (EtOH) (1:1 volumetric ratio). The suspension was homogenized for $2 \mathrm{~h}$ and, as an aid for sintering, 1 and $2 \mathrm{~mol} \%$ of $\mathrm{Bi}_{4} \mathrm{Ti}_{3} \mathrm{O}_{12}$ (BIT) were introduced during the milling. The depositions were made at room temperature using two polished platinum plates $(10 \mathrm{~mm} \times 15 \mathrm{~mm} \times 0.3$ $\mathrm{mm}$ ), which worked as a substrate (cathode) for BTZ15 deposition and counter electrode (anode). The electrodes were placed parallel with a separation of $15 \mathrm{~mm}$ and a voltage of $200 \mathrm{~V}$ was applied. A green-body (deposit) with excellent homogeneity, thickness of $\sim 50 \mu \mathrm{m}$ and a relative green-density of $\sim 50 \%$ was obtained. More details of deposition may be found in Ref. [3].

The experimental apparatus used to make the laser scanning sintering (LSS) is presented in Fig. (1) and consists in a high-power continuous wave (cw) $\mathrm{CO}_{2}$ laser (a) (Synrad 601) which was directed on the pre-heated thick film at $350^{\circ} \mathrm{C}$ in order to prevent thermal shocks (g). The system sample/furnace scanning was performed by a micro-processor controlled X-Y stage (f) and it allows for sinterization of thick films with dimensions up to $70 \mathrm{~mm}$ in length and width of $10 \mathrm{~mm}$. Finally, we have used one $\mathrm{KBr}$ cylindrical lens (d) with the intention to increase the scanned surface. This lens changes the circular laser spot into a line-shaped focus (see insert). The temperatures were monitored throughout the laser scanning process with S-type thermocouple $(0.25 \mathrm{~mm}$ diameter) positioned on the thick film surface (Fig. 2). The thermocouple was attached to the center of the film while it moves under the laser line. The laser power was maintained constant at $37 \mathrm{~W}$ to reach the onset of densification of the BTZ15 $\left(\sim 1230{ }^{\circ} \mathrm{C}\right)[11]$.

The structural investigation and phase formation were done by powder $\mathrm{X}$ ray diffraction technique in a XRD Rigaku Rotaflex RU-200B, using $\mathrm{Cu} \mathrm{K} \alpha$ radiation. The

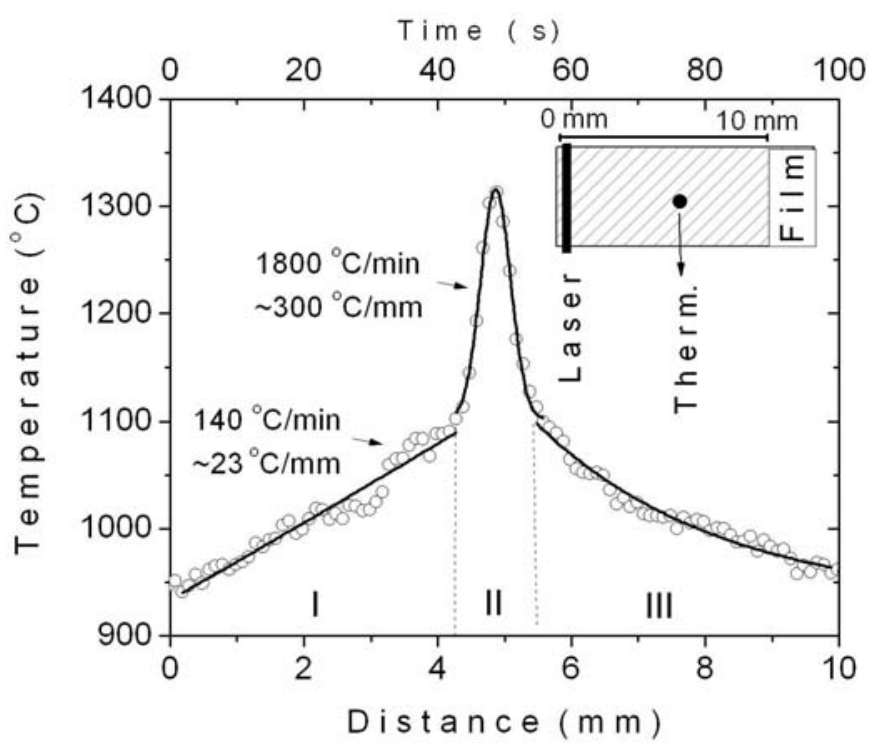

Fig. (2). Monitoring of the temperature dependence on the time/distance during the translation of the laser line in the course of the laser scanning sintering (LSS).

measurements were carried out at room temperature in continuous mode, in the $2 \theta$ range between $20^{\circ}$ to $80^{\circ}$, and in steps of $0.02^{\circ}$. In order to identify and quantify the phases and to determine the cell parameters, the $\mathrm{X}$ ray diffraction profiles were adjusted by the General Structure Analysis System software (GSAS 2004). The Thompson-CoxHastings pseudo-Voigt function was used to define the profile shape while the background was modeled using a Chebyshev function. Overall isotropic displacement temperature factors were used.

Average grain size of the BTZ15 sintered thick films was evaluated by the intercept method [16] directly on the scanning electron microscopy (Zeiss DSM 960). An image analyzer was used to determine the area fraction and consequently the apparent porosity on the polished surface [12].

\section{RESULTS AND DISCUSSION}

The profile temperature obtained during the dynamic process of the LSS is presented in Fig. (2). The laser line is positioned, initially, on the film/substrate distant $6 \mathrm{~mm}$ of the thermocouple (see insert). The scanning speed used was 6 $\mathrm{mm} / \mathrm{min}[12]$. In this case, the temperature increase is due to

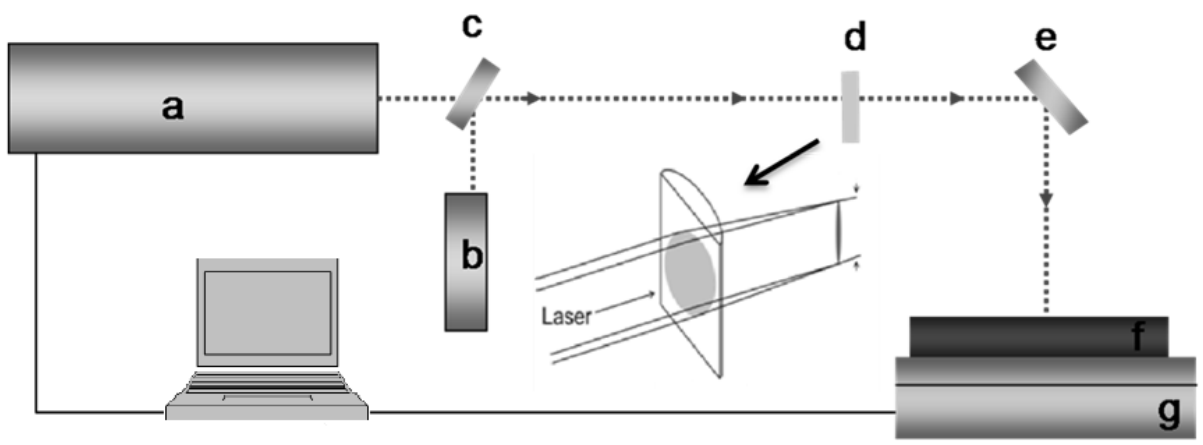

Fig. (1). Schematic representation of the laser sintering system. $\mathbf{a}-\mathrm{CO}_{2}$ laser, $\mathbf{b}-\mathrm{He}-\mathrm{Ne}$ laser, $\mathbf{c}-\mathrm{ZnSe}$ spot divisor, $\mathbf{d}-\mathrm{KBr}$ cylindrical lens, $\mathbf{e}$ - Reflector mirror, $\mathbf{f}$ - Pre-heated furnace, $\mathbf{g}$ - xy translation system. 
the heat transfer between film and substrate. During the translation of the thick film under the laser line $(6 \mathrm{~mm} / \mathrm{min})$ the temperature increase was $140 \pm 20^{\circ} \mathrm{C} / \mathrm{min}$ (Fig. $2-$ I). This heating rate was constant until the position of the laser line has crossed the thermocouple. In this region, the temperature rate changed to $1800 \pm 400^{\circ} \mathrm{C} / \mathrm{min}$ (Fig. 2 - II) and the thick film reached the ideal sintering temperature.

Fig. (3) presents the temperature as a function of the distance of the thermocouple to the laser line (thermal gradient). The thermocouple was positioned in the same way as shown in Fig. (2) and the temperature deviation was estimated in an average of 30 acquisitions with the X-Y stage stopped. As observed in Fig. (3), the temperature profile has two very distinct characteristics (thermal gradients). These temperature gradients can be related to: i) the approximation of the heating source $\left(18{ }^{\circ} \mathrm{C} / \mathrm{mm}\right)$; ii) the fast rise of the temperature due to the translation of the film towards the laser line $(1 \mathrm{~mm}$ in diameter $)\left(255^{\circ} \mathrm{C} / \mathrm{mm}\right)$. As a result, of $\mathrm{i}$ and $\mathrm{ii}$, the thick film is sintered with two distinct heating rates and also two different steps of temperature.

Since the film and substrate present a great difference in its thermal conductivity, initially, in a standstill situation, the laser heats the film locally and below the beam the film reaches temperatures of approximately $1230{ }^{\circ} \mathrm{C}$. At this point, the thermal diffusion in the substrate occurs in the direction of the length of the film. Since the platinum substrate has a thermal conductivity much greater than the BTZ film, this will be responsible for the distribution of temperature $\left(\sim 1000{ }^{\circ} \mathrm{C}\right)$. As a result of this temperature regime, the translation of the laser beam on the thick film can be described as the shift of Fig. (2) curve on the whole thick film.

The morphology and the thickness of the sintered film were examined by scanning electron microscopy. Fig. (4) and Table 1 present the grain size and apparent porosity for pure and BIT-doped BTZ15 (1 and 2 mol \%) for 4 laser scans. Inserted in the Fig. (4), we present the SEM images for the three samples. In all the cases, the films are crack free and presented mechanical resistance. The BIT introduction results in an important porosity reduction. Likewise, the direct comparison between the thick films without and with 1 and 2 mol $\%$ of BIT allows us to observe that the grain size has significantly decreased with the increasing of the BIT content. It was observed a grain size of $200 \mathrm{~nm}$ for BTZ15 $2 \mathrm{~mol} \% \mathrm{BIT}$, which is about twice the size of the starting powder agglomerates (Table 1). This result represents a reduction of approximately $165 \%$ as related to the film without BIT. This is a result that appears to be contradictory with the literature [17]. The densification process from the liquid phase sintering mechanism is generally accompanied by a

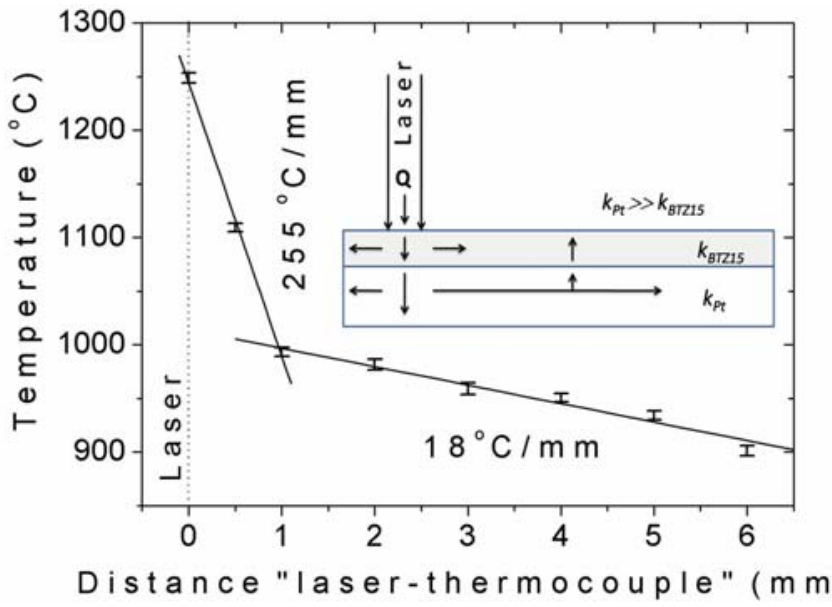

Fig. (3). Temperature as a function of the distance of the thermocouple up to the laser line (thermal gradient). The thermocouple was moved and the deviation was estimated in an average of 30 acquisitions of temperatures with the laser line stopped.

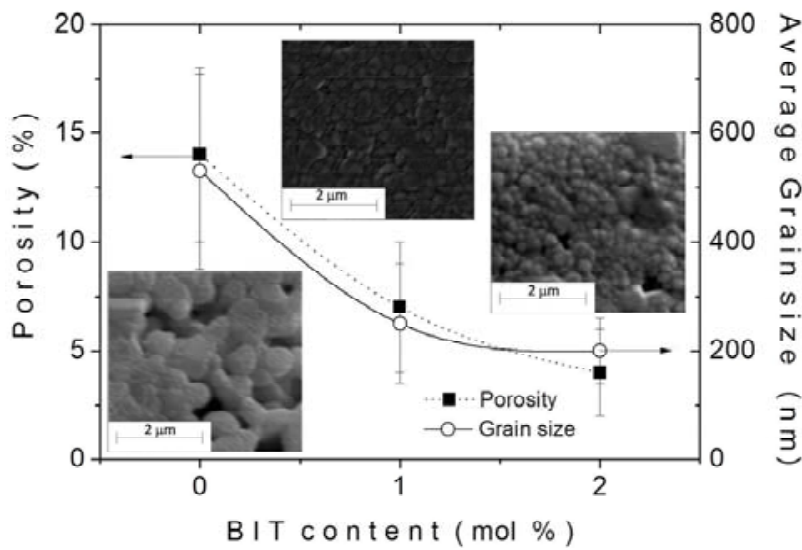

Fig. (4). Porosity and grain size dependence with the BIT value for the LSS thick films. The inserts present SEM micrograph of BTZ15, BTZ15 - 1 mol\% BIT, and BTZ15 - 2 mol\% BIT cut, polished and thermally-etched. 
Table 1. Apparent porosity, grain size and grain growth dependence with the BIT value for the LSS thick films. The grain growth values $(\%)$ were evaluated in relation to the starting powder agglomerates $(\sim 100 \mathrm{~nm})$

\begin{tabular}{|c|c|c|c|}
\hline Thick Film Composition & Apparent Porosity & Grain Size & Grain growth (\%) in Relation to the Agglomerates of $\sim 100$ nm. \\
\hline \hline BTZ15 & $14 \pm 4 \%$ & $530 \pm 180 \mathrm{~nm}$ & $430 \%$ \\
\hline BTZ15 $1 \mathrm{~mol} \%$ BIT & $7 \pm 3 \%$ & $250 \pm 110 \mathrm{~nm}$ & $150 \%$ \\
\hline BTZ15 2mol\% BIT & $4 \pm 2 \%$ & $200 \pm 60 \mathrm{~nm}$ & $100 \%$ \\
\hline
\end{tabular}

small increment of the grain size morphology, becoming abrupt around the melting points with increasing firing temperature $[4,17]$. In fact, it has been recently reported that the BIT introduction in $\mathrm{BaTiO}_{3}$ based materials has resulted in an increase in the grains growth [18].

Since all our samples were sintered in the same conditions, this result can only be related to the thermal process during the LSS. In other words, it is possible to describe the LSS as a two-step sintering, but with a pre-treatment. However, the second-step sintering proceeds in a "frozen" microstructure on the presented conditions of LSS only when BIT is added to BTZ15. In accordance to the two-step sintering process $[5,9]$, the feasibility of densification without grain growth relies on the suppression of grain-boundary migration while keeping grain boundary diffusion active. The kinetic "window" for which this is possible in second-step sintering depends on the density obtained in the first stage of sintering ( $\sim 75 \%$ in density) [5]. In the LSS of BTZ, this density is reached in the first stage only with the BIT introduction. Therefore, the BIT doping had the effect of shifting the kinetic window to a lower temperature thus making possible the grain size decreasing with the BIT introduction.

Fig. (5) shows the XRD patterns corresponding to the LSS thick films prepared with pure (a) BTZ15, (b) BTZ15 $1 \mathrm{~mol} \%$ BIT and (c) BTZ15 - 2mol\% BIT. The cell parameter and phase quantification, performed from the XRD data are shown in Table 2 . The good agreement between the experimental data and the model used in the analysis are evident in the difference curve of each XRD profile (Fig. 5). It was observed for all compositions the formation of a phase compound isostructural with the cubic $(\mathrm{Pm}-3 \mathrm{~m}) \mathrm{BaTiO}_{3}$. Hong-Hsin Huang [19] have studied the tetragonality of $\mathrm{Ba}\left(\mathrm{Zr}_{\mathrm{x}} \mathrm{Ti}_{1-\mathrm{x}}\right) \mathrm{O}_{3}$ ceramics using the Rietveld Method and they observed that both lattice parameters a and continuously approach each other when the $\mathrm{Zr}^{4+}$ is increased. This phenomenon is caused by $\mathrm{Ti}^{4+}$ replacing $\mathrm{Zr}^{4+}$ at the $\mathrm{B}$ site of the perovskite structure, creating an enlargement of the $B$ site and thus a larger increase of the a value than the $\mathbf{c}$ value. However, for $\mathrm{x}=0.15$ the authors observed also some tetragonality $(\mathrm{a} / \mathrm{c}=0.9986)$ that was not detected in our LSS thick films. We believe that this characteristic is associated with the LSS sintering on a rigid substrate (constrained shrinkage) that can result in stress, lattice deformations and tetragonality decrease. Accordingly, the formation of the starting BTZ15 phase may be assumed with a pseudo-cubic symmetry. The secondary phase observed in all the compositions (Fig. 5a-c) is due to the platinum substrate $\left(2 \theta=39^{\circ}\right.$ and $\left.46^{\circ}\right)$.
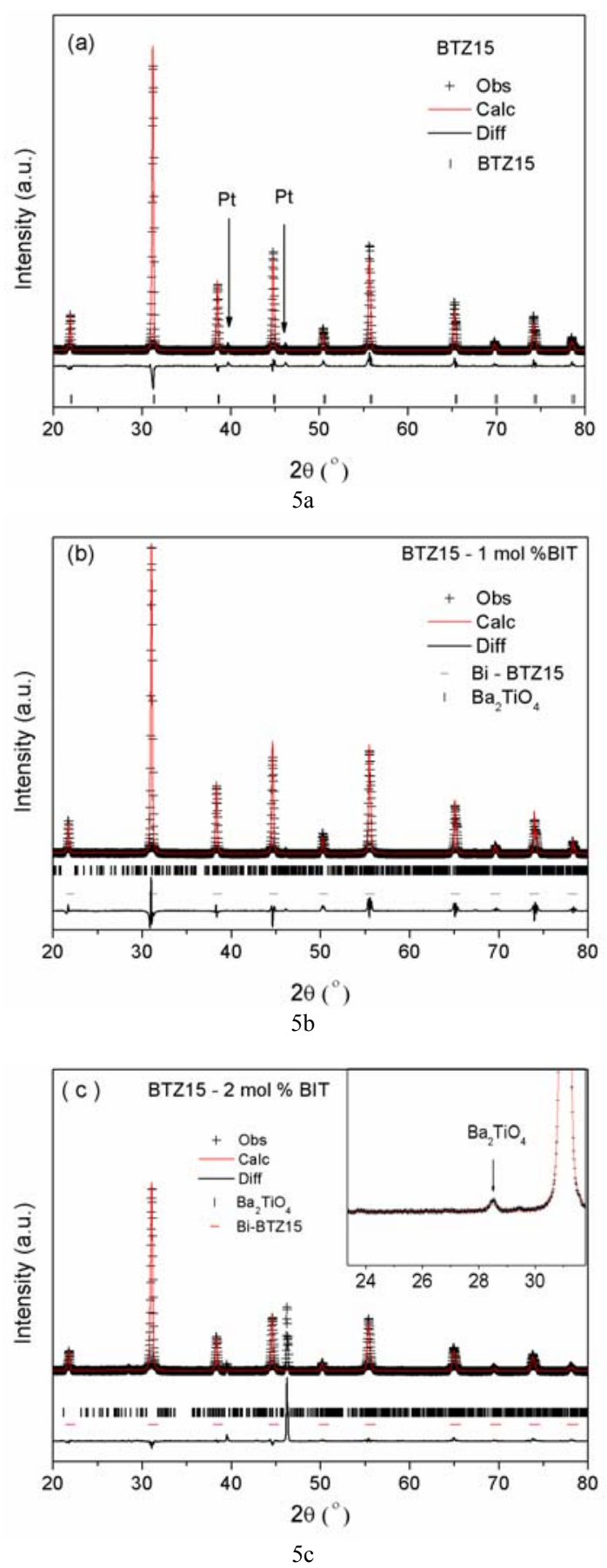

Fig. (5). X-ray diffraction patterns and Rietveld refinement of the LSS thick films prepared with pure (a) BTZ15, (b) BTZ15 $1 \mathrm{~mol} \% \mathrm{BIT}$, (c) BTZ15 - 2mol\% BIT. 
Table 2. Phase Quantification and Cell Parameters Obtained from the X-ray Diffraction Profile Adjusted by the GSAS Software

\begin{tabular}{|c|c|c|c|}
\hline & LSS BTZ15 & LSS BTZ15 1\%BIT & LSS BTZ15 2\%BIT \\
\hline \hline Lattice Parameter $(\AA)$ & 4.0337 & 4.0382 & 4.0530 \\
\hline$\%$ of $\mathrm{Ba}_{2} \mathrm{TiO}_{4}$ & - & $<1.0$ & 1.5 \\
\hline
\end{tabular}

In the present study, the XRD results reveal that the lattice parameter increases with the increasing of BIT content (Table 2). The $\mathrm{Bi}_{4} \mathrm{Ti}_{3} \mathrm{O}_{12}$ (BIT) was added as an aid for sintering ( 1 and 2 mol \%). However, the lattice parameter alterations are an evidence of reaction between the compositions, and a formation of a new compound. We believe that $\mathrm{Bi}^{3+}$ is replacing $\mathrm{Ba}^{2+}$ at the $\mathrm{A}$ sites. This hypothesis is in good agreement with the experimental data, see Fig. (5b and c).

To further understanding the above phase development trend, the possible reaction for BTZ15 - 2mol\% BIT can be presumed as:

$\mathrm{BaTi}_{0.85} \mathrm{Zr}_{0.15} \mathrm{O}_{3}+0.02 \mathrm{Bi}_{4} \mathrm{Ti}_{3} \mathrm{O}_{12}$

if the $\mathrm{Bi}^{3+}$ is incorporate in $\mathrm{Ba}^{2+}$ site, the formulation is,

$\mathrm{Ba}_{1-\mathrm{y}} \mathrm{Bi}_{2 \mathrm{y} / 3} \square_{\mathrm{y} / 3} \mathrm{Ti}_{0.85} \mathrm{Zr}_{0.15} \mathrm{O}_{3}$

and the reaction become,

$\mathrm{Ba}_{0.88} \mathrm{Bi}_{0.08} \mathrm{Ti}_{0.85} \mathrm{Zr}_{0.15} \mathrm{O}_{3}+\left(\mathrm{Ba}_{0.12}+\mathrm{Ti}_{0.06} \Rightarrow 0.06 \mathrm{Ba}_{2} \mathrm{TiO}_{4}\right)$

Meanwhile, Fig. (5b and $\mathbf{c}$ ) indicates the formation of two distinct phases that were identified to be isostructural with the cubic $\mathrm{BaTiO}_{3}$, as major phase, and yet the cubic $\mathrm{Ba}_{2} \mathrm{TiO}_{4}$, as minor phase (insert in Fig. 5c).

The films thicknesses were studied by optical microscopy before and after the sintering. Fig. (6a and b) shows the lateral profile for a thick film (BTZ15 - 1mol\% BIT) sintered in the optimized conditions (solid line). The thick film thickness before sintering (dot line) and the highest temperature in thick film surface (dash dot line) were also shown. The green thick film deposited presented thickness of (50 \pm 5) $\mu \mathrm{m}$. After sintered, the thickness was of $(26 \pm 5) \mu \mathrm{m}$ (Fig. 6a). In detail are shown images of the thick films cut-cross section which present a homogeneous interface between the film and substrate. As can be seen (Fig. 6a) the samples presented a low pores concentration and crack-free microstructure.

We can observe a constant thickness in all extension of the thick film and an edge effect (thicker deposition) in the first $\sim 0.5 \mathrm{~mm}$ (Fig. 6b). This edge effect is attributed to the electric field concentration around the edge of the exposed metal during EPD process which causes a higher powder deposition in this region.

The film shrinkage is constant in the LSS. However, in Fig. (6b) the scanning was stopped before scanning the whole thick film and it was shown the last laser position before turning the laser power off. The dynamic of shrinkage during the scanning can be analyzed after the $3 \mathrm{~mm}$ point (Fig. 6b), where the laser is immediately turned off. It can be observed two steps of contraction: i) one carried out exactly under the laser line, in the maximum temperature ( $40 \%)$; ii) the other shrinkage occurs with the heating front $(\sim 20 \%)$. This is a clear evidence for the two-step sintering process in the laser sintering technique.

\section{CONCLUSIONS}

Thick films of $\mathrm{Bi}_{4} \mathrm{Ti}_{3} \mathrm{O}_{12}$ (BIT) - doped $\mathrm{BaTi}_{0.85} \mathrm{Zr}_{0.15} \mathrm{O}_{3}$ (BTZ15) were successfully sintered using a $\mathrm{CO}_{2}$ laser as heat source. The related thermal process during the laser scanning acted in a similar way as a two-step sintering, and this interpretation may introduce a new form of seeing and work with the laser sintering. The utilization of the system developed for the sintering along with the addition of the BIT resulted in a grain size decrease and a significant decrease in apparent porosity. X-ray diffraction reveals the increase in the cell

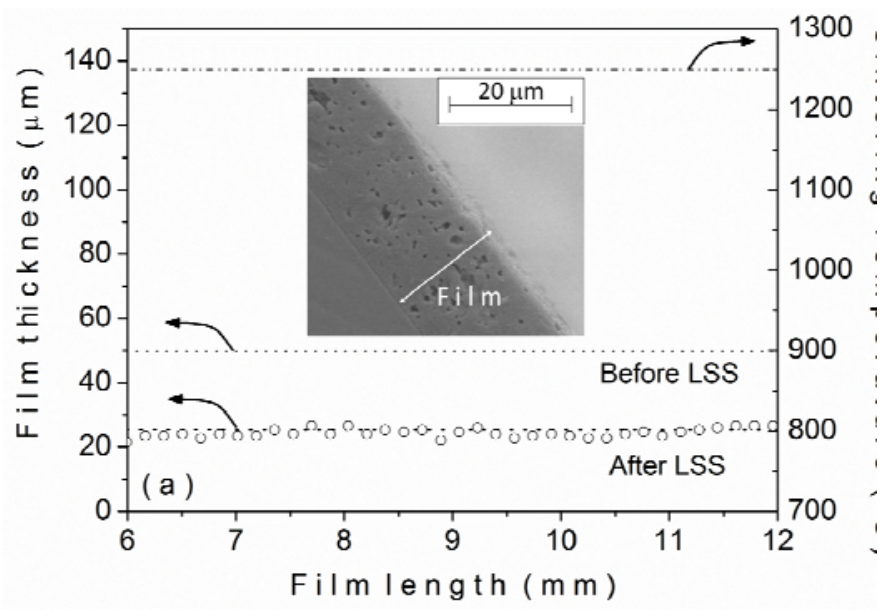

$6 \mathrm{a}$

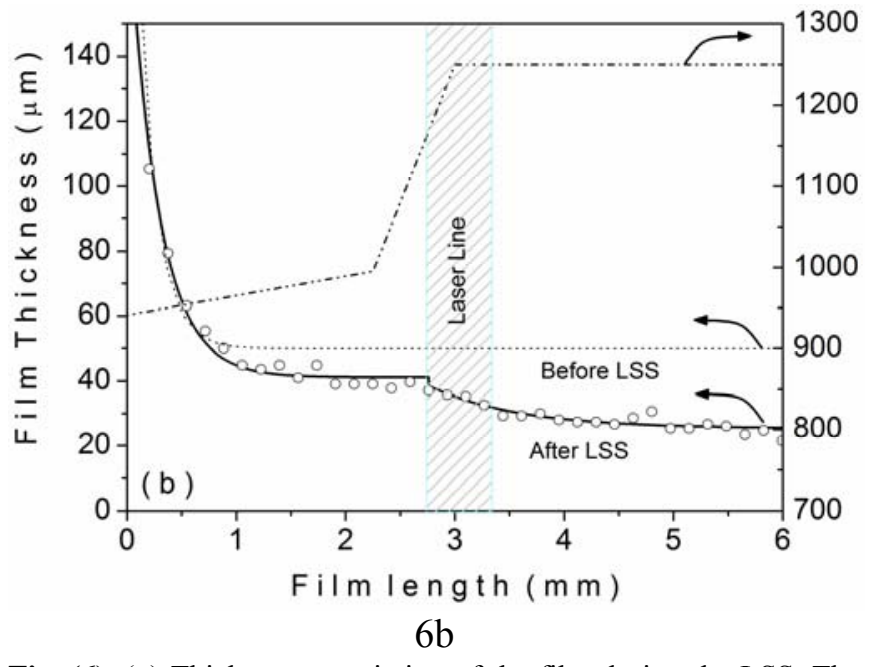

Fig. (6). (a) Thicknesses variation of the film during the LSS. The experimental points were obtained by analysis of optical microscopy images. The insert presents SEM micrograph of the BTZ15 $2 \mathrm{~mol} \%$ BIT thick film cut, polished and thermally-etched. (b) Thicknesses variation of the film during the LSS when the scanning was stopped before scanning the whole thick film. It is indicated in the figure the point where the laser is off $(3 \mathrm{~mm})$. Also it is shown the sintering temperature during the scanning. 
parameters of BTZ15 with the addition of BIT. This is evidence of the reaction between the compositions, and a formation of a new compound, where the $\mathrm{Bi}^{3+}$ is replacing $\mathrm{Ba}^{2+}$ at the A sites. For the $2 \mathrm{~mol} \%$ additivation we obtained films with excellent density (apparent porosity of $\sim 4 \%$ ) and reduced grain size $(\sim 200 \mathrm{~nm})$.

\section{CONFLICT OF INTEREST}

The authors confirm that this article content has no conflicts of interest.

\section{ACKNOWLEDGEMENTS}

The authors acknowledge support from FAPESP and $\mathrm{CNPq}$, two Brazilian funding agencies.

\section{REFERENCES}

[1] Xu B, White D, Zesch J, et al. Characteristics of lead zirconate titanate ferroelectric thick films from a screen-printing laser transfer method. Appl Phys Lett 2005; 87:192902.

[2] Wu A, Vilarinho PM. Electrophoretic Deposition of Lead Zirconate Titanate Films on Metal Foils for Embedded Components. J Am Ceram Soc 2006; 89:575-81.

[3] Antonelli E, Silva RS, Vicente FS, Zanatta AR, Hernandes AC. Electrophoretic deposition of $\mathrm{Ba}_{0.77} \mathrm{Ca}_{0.23} \mathrm{TiO}_{3}$ nanopowders. J Mater Process Technol 2008; 203:526-31.

[4] Messing GL, Stevenson AJ. Toward pore-free ceramics. Mater Sci 2008; 322:383-4.

[5] Wang X-H, Deng X-Y, Bai Hai-Lin, Zhou H, Qu Wei-Guo, Li LT. Two-Step Sintering of Ceramics with Constant Grain-Size, II: $\mathrm{BaTiO}_{3}$ and $\mathrm{Ni}-\mathrm{Cu}-\mathrm{Zn}$ Ferrite. J Am Ceram Soc 2006; 89:438-43.

[6] Charmond S, Carry CP, Bouvard D. Densification and microstructure evolution of Y-Tetragonal Zirconia Polycrystal powder during direct and hybrid microwave sintering in a single-mode cavity. $\mathrm{J}$ Eur Ceram Soc 2010; 30:1211-21.

[7] Locci AM, Cincotti A, Todde S, Orrù R, Cao G. A methodology to investigate the intrinsic effect of the pulsed electric current during the spark plasma sintering of electrically conductive powders. Sci Technol Adv Mater 2010; 11:045005.

[8] Hulbert DM, Anders A, Andersson J, Lavernia EJ, Mukherjee AK. A discussion on the absence of plasma in spark plasma sintering. Scripta Mater 2009; 60: 835-8.

[9] Chen I-Wei, Wang X-H. Sintering dense nanocrystalline ceramics without final-stage grain growth. Nature 2000; 404:168-71.

[10] Waetjen AM, Polsakiewicz DA, Kuhl I, Telle R, Fischer H. Slurry deposition by airbrush for selective laser sintering of ceramic components. J Eur Ceram Soc. 2009; 29:1-6.

[11] Antonelli E, Hernandes AC. Laser scanning sintering of $\mathrm{Ba}\left(\mathrm{Ti}_{0.85} \mathrm{Zr}_{0.15}\right) \mathrm{O}_{3}$ thick films. Cerâmica 2009; 55:94-9.

[12] Simchi A, Godlinski D. Effect of SiC particles on the laser sintering of Al-7Si-0.3Mg alloy. Scripta Mater 2008; 59:199-02.

[13] Macedo ZS, Hernandes AC. A quantitative analysis of the laser sintering of bismuth titanate ceramics. Mater Lett 2005; 59:345661.

[14] Antonelli E, Letonturier M, M'Peko J-C, Hernandes AC. Microstructural, structural and dielectric properties of Er3+-modified $\mathrm{BaTi}_{0.85} \mathrm{Zr}_{0.15} \mathrm{O}_{3}$ ceramics. J Eur Ceram Soc 2009; 29:1449-55.

[15] Bernardi MIB, Antonelli E, Lourenço AB, Feitosa CAC, Maia LJQ, Hernandes AC. $\mathrm{BaTi}_{1-\mathrm{x}} \mathrm{Zr}_{\mathrm{x}} \mathrm{O}_{3}$ nanopowders prepared by the modified Pechini method. J Therm Anal Cal 2007; 87:725-30.

[16] American Society for Testing and Materials - ASTM.E1382. Standard test methods for determining average grain size using semiautomatic and automatic image analysis. v. 03.01. Annual Book of ASTM Standards, ASTM; 1991.

[17] Randall MG. Sintering theory and practice, New York: John Wiley \& Sons 1996.

[18] Jain TA, Chen CC, Fung KZ. Effects of $\mathrm{Bi}_{4} \mathrm{Ti}_{3} \mathrm{O}_{12}$ addition on the microstructure and dielectric properties of $\mathrm{Mn}$-doped $\mathrm{BaTiO}_{3}$-based X8R ceramics. J Alloys Compd 2009; 476:414-9.

[19] Huang H-H, Chiu H-H, Wu N-C. Tetragonality and Properties of $\mathrm{Ba}\left(\mathrm{Zr}_{\mathbf{x}} \mathrm{Ti}_{1-\mathrm{x}}\right) \mathrm{O}_{3}$ Ceramics Determined Using the Rietveld Method. Metallogr Mater Trans A 2008; 39A: 3276-82.

Received: March 04, 2013

Revised: July 22, 2013

Accepted: July 28, 2013

(C) Antonelli et al.; Licensee Bentham Open.

This is an open access article licensed under the terms of the Creative Commons Attribution Non-Commercial License (http://creativecommons.org/licenses/by-nc/3.0/) which permits unrestricted, non-commercial use, distribution and reproduction in any medium, provided the work is properly cited. 